\title{
Sujeição de Direitos, Meio Ambiente e ANTROPOCENTRISMO Alargado
}

\author{
Thiago Felipe de Souza Avanci*
}

\begin{abstract}
1 Introdução. 2 O sujeito, o objeto e as ciências. 3 O direito enquanto ciência. 3.1 Finalidade do direito. 3.2 Sujeito e objeto do direito. 4 Ecovisões e sujeição de direitos. $5 \mathrm{O}$ antropocentrismo alargado como ponto de equilíbrio. 6 Há direito ecocêntrico? 7 Conclusões. Referências.
\end{abstract}

\begin{abstract}
RESUMO
Muitos questionamentos pairam sobre o real papel do ser humano nas ciências e, do mesmo modo, se este papel poderia ser desempenhado por figuras não humanas. Já a partir da modernidade, iniciou-se um vigoroso embate, com altos e baixos, sobre a possibilidade de se atribuir aos animais, à natureza e a outras entidades não humanas o papel de sujeitos de direitos. A partir de algumas ponderações desenvolvidas pela análise do antropocentrismo alargado, o presente trabalho tenciona demonstrar a capacidade de uma ciência com um sujeito humano, porém preocupado com as necessidades do ambiente.

Palavras-chave: Sujeição de direitos. Antropocentrismos. Ecovisões. Biocentrismo. Ecocentrismo.

\section{INTRODUÇÃO}

Desde quando o ser humano identificou-se como sendo artífice no meio que lhe circunda, portanto, modificador, pululou o questionamento do papel do ambiente e dos elementos que o compõem em relação à espécie artesã que detém a capacidade de modificá-lo tão drasticamente. A religião espelha uma primeira tentativa de designar essa relação: "E disse Deus: Façamos o homem à nossa imagem, conforme a nossa semelhança; e domine sobre os peixes do mar, e sobre as aves dos céus, e sobre o gado, e sobre toda a terra, e sobre todo o réptil que se move sobre a terra." (BÍBLIA, Gênesis, 1, 26-30).

* Advogado. Doutorando em Direito pela Universidade Presbiteriana Mackenzie (2017-2020), com bolsa integral. Especialização em Gestão Pública Municipal pela UNIFESP (2017-2018). Mestre em Direito pela Universidade Católica de Santos (UNISANTOS) (2011), com bolsa integral CAPES. Bacharel em Direito pela Universidade Católica de Santos (UNISANTOS) (2007). Professor da Universidade Paulista - UNIP (2014-). Professor do Centro Universitário Monte Serrat (UNIMONTE) (2017-). Revisor da Revista Faculdad de Derecho de Montevideo ISSN 0797-8316 (2014). Revisor de ACDI - Anuario Colombiano de Direito Internacional ISSN 2145-4493 (2014). Presidente da Comissão de Direitos da Criança e do Adolescente da OAB Guarujá (2013-2015). Vice-Presidente do Conselho de Direitos da Criança e do Adolescente de Guarujá (2016-2017).E-mail: <dr.avanci@outlook.com>.
\end{abstract}


Com a ponderação racional do posicionamento humano no universo, naturalmente, nas diversas ciências, a relação entre o ambiente e o ser humano também foi objeto de ponderações. O ser humano é partícipe igualitário do ambiente, devendo respeitá-lo ou, pela sua peculiar condição, deve subjugá-lo à sua vontade despótica? Em verdade, este debate é alheio ao propósito da Ciência do Direito. A Ciência do Direito é construída por normas geradas em função da autodeterminação e a fundamentação ético-filosófica destas normas (o porquê de terem sido feitas) constituem elementos que não dizem respeito ao Direito.

Ao Direito importa a consolidação dos pensamentos ético-filosóficos em normas postas. E, bem assim, encontra-se em normas positivadas uma preocupação com o ambiente ecologicamente equilibrado, elevado, pois, à condição de Direito Fundamental. $\mathrm{O}$ art. 225 da Constituição Federal consagra o meio ambiente como um direito de todos e prescreve um preceito conservacionista que implica, necessariamente, a adoção de técnicas e instrumentos que possibilitem a proteção, a manutenção e a restauração da qualidade ambiental com vistas ao desenvolvimento sustentável.

Desse modo, ao lado de um direito fundamental ao meio ambiente sadio e equilibrado, impõe-se também a existência de um dever de defesa do meio ambiente, compartilhado entre Estado e sociedade civil, baseado em um princípio de solidariedade que emana um compromisso ético para com o futuro e de equidade para com as gerações vindouras.

O objetivo geral deste trabalho é procurar refletir sobre o diálogo da ciência do Direito, na sua condição interpenetradora e regulatória, com outras ciências, com foco especial nas ciências naturais. Assim, a dúvida fundamental é se o Direito sofre alguma alteração em seus elementos estruturantes de ciência ao ser influenciado pelas ecovisões. A pesquisa será encaminhada por uma abordagem dedutiva, por meio de revisão literária, que buscará no pensamento de autoridades; a análise das questões trazidas ao debate.

Para tanto, este trabalho irá analisar, em um primeiro momento, a questão dos elementos que compõem uma ciência, em especial, o sujeito e o objeto. Após essa verificação, passa-se a enquadrar o Direito dentro desse modelo tradicionalmente instituído como ciência; buscar-se-á o sujeito, o objeto e a finalidade do Direito. Isto com o objetivo de constatar qual é o papel do ser humano dentro desta visão científica do Direito e se há alguma mudança estruturante caso o paradigma historicamente antropocêntrico fosse alterado.

Uma vez considerados esses parâmetros, observados os pontos trazidos pelas ecovisões sobre a ciência do Direito, passa-se a analisar um ponto de equilíbrio entre o antropocentrismo extremo e as ecovisões extremas, chegando-se ao denominador comum, que é o antropocentrismo alargado. Com isso, a justificativa desta pesquisa fica evidenciada a partir de reavivar uma polêmica busca por um tema debatido e não exaurido: seria possível, em prol da proteção jurídica ambiental, transformar a natureza em sujeito de direitos? Por meio deste questionamento, a depender da resposta, podem-se causar impactos absolutamente inesperados na sociedade, como um todo, já que o ser humano depende diretamente da natureza, de animais e de vegetais para manter seu status quo. 


\section{O SUJEITO, O OBJETO E AS CIÊNCIAS}

Um gato morto e um gato vivo, simultaneamente. ${ }^{1}$ Esse foi o resultado do experimento mental de mecânica quântica desenvolvido por Schrödinger (1935). A percepção do papel do sujeito-observador nas ciências mudou drasticamente com o advento da mecânica quântica, alçando-o de sujeito alheio ao sistema - em que se compreende também o objeto-observado e o objetivo/finalidade daquela - então vigente pelo modelo cartesiano, para partícipe deste. O simples ato de sujeito-observador praticar a sua observação interfere, por si só, no objeto-observado. Esse novo marco nas ciências puras demonstra que há uma necessária relação entre sujeito e objeto, não estando cada qual isolado no sistema científico.

Ao se verificar, na história, o transcorrer da relação entre sujeito e objeto, podem-se verificar três modelos distintos: um modelo subjetivista, um modelo objetivista e um modelo subjetivo-objetivo. Pelo primeiro modelo, dentro da metafísica aristotélica, um ser era determinado exclusivamente por matéria e forma em potência e em ato, o que veio a ser modificado mais tarde por Tomás, com o acréscimo da essência e da existência. Eis que, dentro desta concepção metafísica do mundo, Aristóteles defendeu um mundo único em que o conhecimento sensível é o único que importa, teoria diametralmente oposta a de seu professor, Platão. Bem assim, somente pelo sujeito-observador é que as coisas efetivamente "são", ou seja, apresentam matéria e forma em ato (ou existência).

Esse pensamento foi modificando-se, encontrando amparo na filosofia de Descartes. O método dedutivo, puramente silogístico, foi alterado para um método experimental-metodológico, portanto indutivo, trabalhado inicialmente por Galileu e seguido por Bacon, Hobbes, Locke e Hume, empirismo que se seguiu ao racionalismo de Descartes e Newton. Em verdade, o sujeito cartesiano existe já que pensa; pensa e se indaga sobre os acontecimentos do mundo; porque se não se indagasse, não existiria e vice e versa. Tal ato de pensar do sujeito-observador ocorre independentemente do existir do objeto-observado. Eis aí o segundo modelo, em que o objeto observado passa a estar isolado do sujeito-observador. Cabe apenas ao sujeito relatar aquilo que as coisas são, objetivamente.

E o modelo cartesiano perdurou até os meados do séc. XIX, quando, de acordo com Elia, o físico Boltzmann realizou descobertas relativas à Segunda Lei da Termodinâmica, demonstrando que a "irreversibilidade dos fenômenos da natureza, é probabilística e não determinista, e depende do número de partículas envolvidas." (ELIA, 2007, p. 6). Essa descoberta coloca em cheque a objetividade cartesiana, na medida em que a ciência passa a contar com a incerteza como sendo uma variável em relação ao objeto, o que faz que o sujeito-observador necessite se reaproximar do sistema.

A mecânica quântica e a mecânica relativista - relata Elia (2007) - substituíram a cartesiana mecânica de Newton, com aplicação na observação das partículas em velocidade próxima à da luz. Dadas as grandezas trabalhadas, pelo indeterminismo próprio deste ramo da física, deixa-se de constatar uma das grandezas atinentes ao sistema: ou se mede o lugar 
(espaço), ou se mede a velocidade; ou se mede a energia, ou o tempo etc. Em outras palavras, as partículas que servem para a excitação dos sentidos do sujeito-observador estão em um mesmo nível da do objeto-observado, o que causa uma interferência com o sistema. É o terceiro modelo de relação entre sujeito e objeto.

Reside aí a resposta para a colocação inicialmente proposta. $\mathrm{O}$ físico austríaco Erwin Schrödinger propôs um experimento mental, conhecido pelo nome de "Gato de Schrödinger." A proposta do físico era criar um sistema isolado, uma caixa. Dentro desta caixa, uma substância radioativa em quantidade muito pequena, que tem igual probabilidade de decair (liberar radiação) ou não. Se a substância liberar radiação, um contador Geiger, dentro da caixa, irá acionar um mecanismo que liberará um ácido que matará o gato. Por outro lado, se a substância não decair, o gato continuará vivo. Ocorre que o sistema ficará isolado, e o simples fato de o sujeito-observador abrir o sistema para eliminar a incerteza irá interferir no resultado do experimento. Com isso, Schrödinger apresentou como sendo a melhor resposta para o experimento um estado denominado "entrelaçamento quântico" (verschränkung), bem assim, um gato vivo e morto ao mesmo tempo.

É importante ressaltar que há diferenças entre a relação sujeito-objeto nas ciências puras e nas ciências aplicadas. Na relação sujeito-objeto das ciências puras, o fim ou objetivo será sempre a busca pela verdade. Porém, nas ciências aplicadas, o fim de cada qual será especificamente direcionado às necessidades aplicadas. Longe de um modelo cartesiano ou aristotélico, a sujeição e o objeto interagem reciprocamente com um propósito: o objeto se molda às necessidades do sujeito para realizar o fim. Amoldado nesta premissa, é possível compreender a Ciência do Direito dentro de um panorama que justifique sua sujeição antropocêntrica.

\section{O DIREITO ENQUANTO CIÊNCIA}

Para identificar o Direito como uma ciência aplicada, é necessário constatar os três elementos que compõem a estrutura metodológica de uma ciência aplicada: o sujeito, o objeto e a finalidade. E, como já se explicou, o modelo das ciências aplicadas não é a pura identificação das verdades naturais, até mesmo porque tais dogmas, nestas espécies de ciências, são questionáveis no seu nascimento. Parece ser uma visão limitada afirmar que o Direito se constitui de uma mera busca e aplicação de direitos naturais, quando nem sequer se pode precisar o que são direitos naturais. Pautado, assim, em um paradigma mais objetivo, há de se perceber o Direito como uma ciência com outra finalidade.

Deveras, há tantas teorias que justifiquem o Direito, quantos autores que sobre este tema escrevam. Del Vecchio (1960), adaptando Kant, erigia seu jusnaturalismo na capacidade de autoafirmação do homem a qual era pautada em sua liberdade. Igualmente, Alexy (2008) e Romano (1977). Kelsen $(1976,1996)$ em seu purismo, Miaille (2005) com sua crítica à vinculação do Direito à justiça e Ross (2003), refutando a moralidade como matriz 
para o Direito, entendiam que a norma era fim em si mesma. Hervada (2006) parte em direção contrária, pautando sua teoria na justiça como instrumento consagrador do direito subjetivo. Ferrajoli (2009) identifica como sendo a igualdade que se realizará na democracia constitucional derivada do modelo de contrato social. Há, ainda, posicionamento, como contido na Declaração de Haia sobre o ambiente de 1989, de que o direito de viver é aquele do qual derivam todos os outros direitos. ${ }^{2}$

E demonstra ser interessante partir-se de premissa de Hart sobre o tema, em que deveria ser abandonada a ideia de que o sistema jurídico consiste em mero hábito de obediência (HART, 1977). Esse pensamento de Hart indica que o Direito não existe apenas com um propósito de impor, portanto, o que excluiria a norma como finalidade do Direito. E, nesse sentido, tudo leva a crer que a liberdade, a igualdade e a vida constituem premissas a serem realizadas dentro de um sistema que os precede. Finalmente, a justiça, embora muito próxima com a ideia do Direito enquanto ciência, por sua intangibilidade, acaba perdendo força ante a dificuldade de defini-la.

\subsection{FINALIDADE DO DIREITO}

Interpretando a ideia de Hart acima exposta, o Direito não existe por si só, existe porque é necessário. Liberdade, norma, justiça, democracia, enfim, todos esses elementos do Direito são parte de um grande sistema científico que objetiva garantir a Dignidade Humana. Eis que soergue um problema: não seria Dignidade Humana um valor tão intangível quanto e.g. a Justiça? Tudo irá depender da compreensão de Dignidade Humana. Se for adotada uma percepção objetiva de Dignidade Humana, pode-se trabalhar com este conceito sem que se gerem incertezas e impropriedades.

Nesse sentido, a ideia de Dignidade $\mathrm{Humana}^{3}$ tem nascimento com a própria compreensão da natureza humana enquanto ser pensante. Fica claro, na Instrução do Vaticano Dignitas Personae e na Encíclica Rerum Novarum, que a Dignidade Humana deriva da criação do ser humano por Deus, da imagem e da semelhança do Deus-Filho, por meio de quem o homem pode ser Filho de Deus. Assim, nada que vem do sagrado e tem potencial para retornar ao sagrado merece qualquer coisa menos do que dignidade. Na verdade, essa acepção religiosa da dignidade humana, longe de ser nascida no cristianismo, já era encontrada desde o judaísmo primitivo, observado em Gn. 2,7, quando YHVH moldou, a partir de adamah (terra fértil e cultivável), Adam (o homem), à sua própria imagem.

Dos filósofos do início da modernidade, o italiano Pico della Mirandola foi um dos primeiros autores, já no séc. XV, a estudar mais atentamente a temática, sob uma perspectiva mais próxima ao Direito. Pautado em estudos da Cabala judaica, do Corão islã e dos Diálogos de Platão, Pico della Mirandola, ao escrever Oratio de hominis dignitate, desenvolveu a ideia de que a Dignidade Humana decorre, notadamente, da liberdade que Deus concedeu ao ser humano e, implicitamente da racionalidade que faz o homem evoluir a filhos de Deus, 
em contrapartida à emoção que os lega às bestas. ${ }^{4}$ Mirandola apresenta argumentos que merecem atenção. Afastando a conotação religiosa de seu texto, observa-se que a liberdade defendida é o motivo imediato que torna o ser humano especial, um camaleão que haveria de ser admirado por todos, ${ }^{5}$ preferido até em relação aos anjos. Pelo movimento Renascentista, outro motivo, menos evidente, é apresentado como motor da força humana, a razão frente à emoção.

Possivelmente, Kant foi o primeiro a dar concretude jurídica (mais aproximado ao Direito hodierno) ao conceito de Dignidade Humana com a necessária profundidade, afirmando que "a ideia da dignidade de um ser racional [...] não obedece a nenhuma outra lei que não seja, ao mesmo tempo, instituída por ele próprio.” (KANT, 2006, online). E continua apresentando como seu fundamento lógico à Dignidade: tudo o que existe possui ou um preço ou uma dignidade; se uma coisa possui um preço, pode ser substituída por outra coisa equivalente; tal não é possível com a Dignidade, que não possui equivalente, estando, assim, acima de todo preço.

Abbagnano (1982), reconhecido também por pesquisa de Garcia, opera conceito pela fórmula categórica de Kant para a Dignidade Humana: "Age de tal forma que trates a humanidade, tanto na tua pessoa como na pessoa de qualquer outro, sempre também como fim e nunca unicamente como um meio." (GARCIA, 2004, p. 196-197, nota 101). Esse pensamento reforça a ideia da infungibilidade da Dignidade Humana e de como é colocada "infinitamente acima de todo preço, com o qual não pode ser nem avaliada nem confrontada, sem que de algum modo se lese sua santidade" (KANT, 2006, online). Nessa linha de raciocínio, Garcia conceitua, com muita felicidade, como sendo "a compreensão do ser humano na sua integridade física e psíquica, como autodeterminação consciente.” (GARCIA, 2008, p. 84).

Chega-se, assim, a um conceito jurídico sólido de Dignidade Humana, seguindo, assim, a linha positiva deste estudo: é a pura autodeterminação enquanto valor fático. É apreensível que inexiste qualquer vislumbre de moralidade, religiosidade ou quaisquer outras filosofias que procurem justificar uma supremacia humana. Dentro de uma ideia aproximada a esta noção individualista, a concepção comunitarista de Dignidade exsurge sintetizada por Ricoeur (2008): o reconhecimento, um dado fático sobre o qual se possibilitaria erigir uma ciência.

De qualquer forma, em uma postura individualista, é justamente nessa ausência de debate sobre a posição - central ou não - do ser humano no universo (própria das concepções religiosas ou metafísicas) que consagra a teoria da autodeterminação no ideário pós-positivista. Düring também tratou do tema, com profundidade, principalmente no pós-guerra alemão. Chegou, também, à conclusão de ser a autodeterminação característica central para um ser humano. Derivado de seu pensamento jurídico próprio difere, no entanto, por atribuir valoração especial ao ser humano, na medida em que:

Cada ser humano é humano por força de seu espírito, que o distingue da natureza impessoal e que o capacita para, com base em sua própria decisão, tornar-se consciente de si mesmo, de autodeterminar sua conduta, bem como 
de formatar a sua existência e o meio que o circunda (DÜRING, 1956, p. 125 apud SARLET, 2010, p. 46). ${ }^{6}$

Pautando-se, assim, na Dignidade como finalidade a ser atingida na Ciência do Direito, a consequente relação entre sujeito e objeto torna-se perceptível.

\subsection{SUJEITO E OBJETO DO DIREITO}

O Direito se justifica, ao que tudo indica, partindo do pressuposto de que a autodeterminação é decorrente da racionalidade e do livre arbítrio. A racionalidade do ser humano é sua capacidade de projetar seu pensamento com lógica, condição que permite superar o instinto ou a reação condicionada. O livre arbítrio, de outra sorte, é a liberdade de o ser humano escolher entre possibilidades diversas, qual será a sua ação. Ambos, racionalidade e livre arbítrio, interdependentes, são os elementos que combinados justificam a criação de uma ciência normativa imputativa. Em outras palavras, racionalidade e livre arbítrio desencadeiam a necessidade de se determinar um comportamento específico ao ser humano. Hervada bem afirma que "o que possibilita o homem ser sujeito de direitos [...]" reside no fato de o homem não se movimentar "[...] exclusivamente por forças e instintos biológicos; em última instância, o homem é responsável por seus atos pessoais, porque pela razão e pela vontade decide livremente." (HERVADA, 2006, p. 55-56). Nesse sentido, doutrinava Kelsen, afirmando que o Direito é uma ciência normativa imputativa, em que se definem normas feitas por seres humanos e para seres humanos, com o objetivo de imputar um "dever ser" à conduta humana, que é pautada no livre-arbítrio e na racionalidade.

O Direito se erige, de acordo com essa ideia positiva, sobre a autodeterminação humana, decorrente do livre arbítrio e da racionalidade, imputando ao ser humano exclusividade na dotação de direitos e obrigações. Enquanto umas ciências sociais estudam e analisam as normas valorativas como motivadoras comportamentais, outras o fazem acerca de normas físicas, químicas ou biológicas e suas consequências em seus respectivos campos, outras, ainda, lidam com o normativo Divino e as suas consequências sobre o ser humano. O Direito opera estritamente por meio de imputações normativas feitas por seres humanos para se estipular uma conduta a ser seguida.

Kelsen chegou a afirmar que

É necessário admitir que o homem tem uma vontade livre, isto é, não determinada causalmente" como forma de explicar "por que é que apenas consideramos ético-juridicamante responsável o homem e não as coisas inanimadas, os fenômenos da natureza ou os animais - para explicar porque é que apenas consideramos imputável o homem (KELSEN, 1996, p. 107).

E continuou, afirmando que

Apenas consideramos imputáveis os homens porque e na medida em que as ordens morais e jurídicas apenas prescrevem condutas humanas porque se admite que a representação das suas normas somente no homem provoca atos de 
vontade que, por sua vez, causam a conduta prescrita. A explicação não está, portanto, na liberdade, mas, inversamente, na determinação causal da vontade humana (KELSEN, 1996, p. 108).

Diferentemente da intelecção da teoria de Kelsen, ${ }^{7}$ no entanto, em um pensamento mais aproximado com os ideários modernos do pós-positivismo, a norma não é o Direito nem tampouco seu objeto. A norma é a ferramenta, o objeto do qual o Direito se vale para ver concretizado seu objeto. A norma é o que definirá o comportamento a ser seguido pelo ser humano, ou seja, a imputação de comportamento. Em razão disso, é possível afirmar que o Direito é uma ciência imputativa normativa. Assim sendo, chega-se a uma conclusão de que a norma decorre da capacidade humana de autodeterminação (que provém da racionalidade e do livre-arbítrio) com o objetivo de se fazer respeitar, em princípio, a própria autodeterminação em sua acepção de valor jurídico, a Dignidade Humana. ${ }^{8}$ Isso indica e denota a dupla faceta do Direito: realizar a autodeterminação e restringir a autodeterminação, uma não ocorrendo sem a outra.

Por força de consequência, cada norma existente no Direito terá o condão de realizar, direta ou indiretamente, a Dignidade Humana. Em razão disso, chega-se ao posicionamento pós-positivista contrário à ideia clássica de que a norma é o Direito. É possível pensar no próprio Estado, enquanto ficção jurídica, como meio para a realização do objeto do Direito. Avançando um pouco mais no pensamento lógico, é em função da autodeterminação humana que o Direito é antropocêntrico.

Assim, uma conclusão pode ser inferida: o ser humano ser sujeito de direitos não decorre do fato de ele ser objeto da tutela de direitos. Um determinado direito ser tutelado por uma norma é expressão da capacidade humana de se autodeterminar. E pode ser o objeto central desta norma tutelada qualquer bem jurídico que se queira. Isso coloca em uma delicada perspectiva o posicionamento pós-moderno de tentar expandir a "sujeição de direitos" às visões ecocêntricas.

\section{ECOVISÕES E SUJEIÇÃO DE DIREITOS}

Note-se, pois, que o fato de o Direito tutelar bens jurídicos distintos do humano (e.g. animais, vegetais, natureza) não torna esta Ciência biocêntrica ou ecocêntrica. A Ciência do Direito continua sendo antropocêntrica porque é destinada a impor comportamento humano por meio de normas.

Superficialmente analisada, assim, a questão da tutela dos bens jurídicos, observa-se que três são os modelos que servem de paradigma para o Direito, conforme ensina Leite (2007). No que tange à sujeição do Direito, o primeiro modelo, antropocêntrico, "economicocentrico reduz o bem ambiental a valor de ordem econômica", afastando-se, assim, de uma preocupação ambiental que não gere lucro imediato. O segundo modelo, o antropocentrismo alargado, "centra a preservação ambiental na garantia da dignidade do próprio ser humano", 
constituindo-se em modelo alargado justamente porque esta proteção ambiental é necessária para a "sobrevivência da própria espécie humana." (LEITE, 2007, p. 137). Finalmente, um terceiro modelo, a ecologia profunda, nas palavras de Capra, "não separa os seres humanos - ou qualquer outra coisa - do meio ambiente natural.” (CAPRA, 2006, p. 31), (LEITE, 2007, p. 139), havendo por se constituírem todas as coisas existentes em uma interconexão e interdependência, o que ressaltaria o valor intrínseco de cada coisa e cada ser.

Também apresentando três fases, Ferry (2009) explica as tendências do ambientalismo: o movimento ambientalista de natureza democrática visa a proteger os interesses do homem, por meio da proteção da natureza. Esta não tem valor intrínseco, mas sua degradação constitui perigo para os seres humanos; a segunda fase, utilitarista, defende que o sofrimento dos animais deve ser considerado moralmente, tal e qual o sofrimento humano. Os animais são sujeitos de direito, e é esta a justificativa usada na defesa dos interesses animais; a terceira atribui à própria natureza os direitos, incluindo sua acepção não animal. Esta seria a tendência da ecologia profunda.

Desde a década de 1970, o Direito tende a migrar de um antropocentrismo economicocêntrico para o antropocentrismo alargado, porém sempre antropocêntrico em sua sujeição. Ainda que defenda valores da ecologia profunda em seu bojo (conteúdo comum), a sujeição é sempre antropocêntrica.

No entanto, amparado por uma base filosófica nascida no Século XVIII, questiona-se o porquê de o Direito ser antropocêntrico (ainda que em modelo alargado) quando, à mercê de uma visão holística, deveria ser ecocêntrico. Esse questionamento filosófico se inicia, pode-se dizer, com Bentham, consagrado na frase na nota 122 de An Introduction to the Principles of Morals and Legislation de 1798: A questão não é podem os animais raciocinar; nem podem eles falar; mas sim eles sofrem? (BENTHAM, 1907). ${ }^{9} \mathrm{O}$ filósofo-jurista inglês concentra sua crítica no fato de as ciências focarem na racionalidade humana como critério de superioridade da raça humana sobre as demais espécies. A ideia de Bentham é filosoficamente perfeita, porém não aplicável à ciência do Direito. Mesmo Bobbio chegou a afirmar que "[olhando para o futuro, já podemos entrever a extensão da esfera do direito [...] a novos sujeitos, como os animais, que a moralidade comum sempre considerou apenas como objetos, ou, no máximo, como sujeitos passivos, sem direitos.” (BOBBIO, 1992, p. 63).

Teorizando positivamente, o Direito não é antropocêntrico em função da racionalidade humana, mas sim em função da autodeterminação humana que resulta em imputação normativa da qual decorrem os direitos subjetivos e as obrigações. O Direito, enquanto ciência, existe com o fim de regrar, por meio de sua normativa, um comportamento humano que satisfaça a realização da Dignidade Humana. De se esclarecer que esta necessidade normativa existe em função do livre arbítrio e da racionalidade humana, decisivo à autodeterminação, por isso destinada exclusivamente ao ser humano.

O Direito não tem como condão a valoração moral. Não parte, assim, da premissa de que o ser humano, por ser racional, é o centro de tudo; parte, sim, da premissa de que suas 
normas são destinadas aos seres humanos porque criados por seres humanos, para atribuição de comportamento aos seres humanos. Assim, se a própria normativa humana impõe que se respeitem determinados interesses não humanos, fá-lo com base na autodeterminação.

Tem-se, pois, que o Direito existe com o objetivo de imputar condutas porque o ser humano é racional e porque possui livre-arbítrio. É diferente e sem sentido, de acordo com o pensamento positivo, afirmar que o Direito existe porque o ser humano é racional. Toda a ciência existe em função da racionalidade humana, mas somente o Direito possui o condão de imputar. Com propriedade, Fiorillo bem acentua que "o direito ambiental possui uma necessária visão antropocêntrica, porquanto o único animal racional é o homem, cabendo a este a preservação das espécies, incluindo a sua própria", e que "não se submete o animal à crueldade em razão de ele" (ser humano) "ser titular do direito, mas sim porque essa vedação busca proporcionar ao homem uma vida com mais qualidade." (FIORILLO, 2006, p. 16-17, passim).

\section{O ANTROPOCENTRISMO ALARGADO COMO PONTO DE EQUILÍBRIO}

François Ost (1997) adverte que a crise ecológica vai muito além de mera destruição dos recursos ambientais, situando-se em um panorama mais profundo relativo à concepção que rege a relação do homem com a natureza.

No âmbito dessa crise referente ao vínculo com a natureza e à necessidade de limites em relação a ela, Ost (1997) enfatiza que o homem alterna extremos antitéticos e reciprocamente equivocados ao tratar a natureza ora como objeto ora como sujeito das relações jurídicas.

Esses extremos de coisificação, baseada no antropocentrismo clássico ou na personificação da natureza, fundamentada na ecologia profunda, acabam revelando a crise de vínculo que pode desprezar a natureza (no caso da natureza-objeto) ou sujeitar o homem à sua vontade (no caso da natureza-sujeito) (OST, 1997).

A síntese entre essas perspectivas éticas é trabalhada por François Ost na concepção natureza-projeto calcada em uma perspectiva de justiça que, longe de absolutizar o sujeito e o objeto, os coloca em relação, abrindo-os um ao outro sem importar em sua confusão. Para o autor, "o que contará, a partir de agora, mais do que a identidade do objeto ou do sujeito, é a relação ou tensão que os constitui, o elo que os une.” (OST, 1997, p. 272-273).

Diante dessa perspectiva de uma nova relação ética entre homem e natureza frente aos antagonismos e aos extremos existentes, Leite (2003, p. 76) destaca o antropocentrismo alargado como mecanismo mediador frente a essas visões, representando o abandono de ideias de separação, dominação e submissão de maneira a buscar-se "uma interação entre os universos distintos e a ação humana."

De uma maneira geral, a concepção do antropocentrismo alargado acaba por ensejar um aprimoramento da responsabilidade humana frente à natureza, compreendendo o homem como guardião da biosfera de modo que a tutela ambiental passe a abranger não apenas o 
que fornece algum proveito econômico mas também toda a capacidade funcional ecológica do patrimônio natural (SENDIM, 1998).

No mesmo sentido, Leite (2003, p. 77) afirma o seguinte:

[...] a perspectiva antropocêntrica alargada propõe não uma restritiva visão de que o homem tutela o meio ambiente única e exclusivamente para proteger a capacidade de aproveitamento deste, considerando precipuamente satisfazer as necessidades individuais dos consumidores, em uma definição economicocêntrica. Com efeito, esta proposta visa, de maneira adversa, a abranger também a tutela do meio ambiente, independentemente da sua utilidade direta, e busca a preservação da capacidade funcional do patrimônio natural, com ideais éticos de colaboração e interação.

Apesar de estabelecer uma conexão direta do meio ambiente em relação à qualidade de vida, a Constituição Federal, em seu art. 225, acaba por acolher a perspectiva ética do antropocentrismo alargado, em razão de se verificarem disposições que tutelam a flora, a fauna, os ecossistemas e os processos ecológicos como elementos dotados de valor intrínseco e autônomo em relação aos interesses diretos do homem.

Ao abordar essa questão, Mirra (2002, p. 59) assevera que o ordenamento brasileiro reconhece o meio ambiente como "valor digno de proteção enquanto tal", já que a proteção à totalidade de elementos ou fatores naturais, artificiais e culturais que condicionam a vida corresponde a "levar em consideração tudo o que a envolve e influi, como objeto de proteção jurídica.”

Reconhecendo que a promoção do bem-estar da humanidade passa a compartilhar seu espaço no sistema jurídico com todas as formas de vida, Ayala (2004) defende que o que se deve procurar é a consideração jurídica da natureza, e não sua personificação.

Nessa perspectiva, a consideração jurídica da natureza corresponde à sua compreensão como bem jurídico entendido na noção de objeto de imputação. Nesse sentido, a dignidade jurídica da natureza será materializada na sua qualidade de bem ambiental, tendo em vista que, como centro de imputação, também será como qualidade jurídica fundamental beneficiária de atividades de garantia (AYALA, 2004).

Nesses termos, o advento da concepção do antropocentrismo alargado e seu respectivo acolhimento na tutela jurídica do meio ambiente representa a inserção de novos valores e a conjugação de novos interesses no sentido de balancear a estrutura jurídica frente ao advento do desafio de uma nova postura ética em relação à questão ambiental.

Por meio do antropocentrismo alargado, a natureza passa a ser objeto de uma consideração jurídica no intuito de se institucionalizar deveres ecológicos tendentes a ensejar o respeito aos seus atributos e valores intrínsecos.

Com base nesse postulado ético conciliatório, verifica-se que a disciplina jurídica do meio ambiente possui um perfil que permite a defesa da natureza sem absolutizá-la como objeto ou como sujeito, mas mantendo canais abertos, com uma visão holística, que oferecem proteção aos recursos naturais (microbem) e a toda sua cadeia de interrelações (macrobem) de forma a harmonizar valores humanos e não humanos. 


\section{HÁ DIREITO ECOCÊNTRICO?}

Um ponto também apresentado como justificativa ao biocentrismo (CASTRO, 2008; SOFFIATI, 2009) é afirmação de que "o princípio da vida é uno." Eticamente, filosoficamente, teologicamente, o princípio da vida é ou pode ser uno, dependendo de quem o valore. Não há como sustentar a unidade do princípio à vida de diferentes espécies como fundamento para a sujeição de uma Ciência que existe em função da autodeterminação de uma única espécie. Não cabe ao Direito positivamente estudado impor ao ser humano valores morais que sirvam para atribuir às espécies não humanas uma equiparação forçada com o ser humano.

Ora, se o Direito serve para impor comportamento aos seres humanos, seria possível pensar em uma norma destinada ao animal ou ao vegetal? O ser humano pode criar uma norma destinada a si: "Matar alguém. Pena - reclusão, de seis a vinte anos." ${ }^{10}$ No entanto, $a b$ absurdo, poderia o Direito criar uma norma para os cachorros: Morder um ser humano. Pena - represália vigorosa com um chinelo. Tal não seria possível justamente pela impossibilidade de se equiparar, por razões biológicas, o ser humano ao cachorro. Mas perceba-se que há possibilidade de se criarem normas que protegem os animais de maus-tratos, por exemplo, sem condicioná-los à surreal situação de sujeitos: "Praticar ato de abuso, maus-tratos, ferir ou mutilar animais silvestres, domésticos ou domesticados, nativos ou exóticos: Pena - detenção, de três meses a um ano, e multa." 11

Canotilho tece interessante comentário sobre o assunto, en passant, ao afirmar que há tendência de mudança na "responsabilidade antropocêntrica" para "responsabilidade ecocêntrica" (CANOTILHO, 2007, p. 7), o que parece indicar uma posição contrária ao antropocentrismo jurídico. Note-se, no entanto, que Canotilho não utiliza a expressão "sujeitos de direito", mas sim responsabilidade e reconhecimento do valor intrínseco da natureza. Assim, assumir que o Direito defenda posição ecocêntrica ou biocêntrica difere completamente de afirmar-se que o Direito reconhece sujeição ecocêntrica ou biocêntrica. Na primeira situação, a sujeição de Direitos continua antropocêntrica, reconhecido, no entanto, que, para a realização da Dignidade Humana e em função de sua autodeterminação, é necessária a proteção de determinados valores e interesses ecocêntricos ou biocêntricos. Na segunda situação, há uma verdadeira colisão de direitos insolvível, com dois sujeitos de Direito distintos "clamando" pela aplicação de seu Direito.

Por outro lado, Benjamin adota posição ousada pautada em uma ideia de solidariedade interespécies e perante a natureza, o que proporcionaria uma visão holística do Direito, afastando-se do Direito welfarista. Inicialmente, afirma que, em função de "valor intrínseco à natureza", o ser humano deveria romper com o paradigma contratualista ${ }^{12}$ (BENJAMIN, 2007, p. 85-111, passim), atribuindo, nas palavras de Rodrigues, direitos de cujas "todas formas de vidas são seus titulares" (RODRIGUES, 2002, p. 61). Bem assim, afirma Benjamin que o constituinte brasileiro de 1988 adotou técnica antropocêntrica mitigada, uma vez que incorporou aspectos estritamente antropocêntricos (proteção à presente e às futuras gerações, conforme caput do art. 225 da Constituição), bem como filiação biocêntrica (citando como exemplo a "noção de 'preservação', no caput do art. 225") (BENJAMIN, 2007, p. 110). 
A atribuição de sujeição à natureza e a outros seres vivos não se dá em função de um paradigma contratualista. Biocentrismo ou ecocentrismo não são possíveis porque, em ambos os casos, haveria uma desigualdade insuprível em relação àqueles outros seres. A pessoa é dotada de autodeterminação, que a faz único sujeito de direitos, revestindo-o com a consequente Dignidade. Assumir que outros seres vivos sejam sujeitos de direitos seria criar uma ficção insustentável dentro do Direito, uma vez que tais seres não possuem autodeterminação e, consequentemente, para o Direito, não possuem Dignidade própria. Cumpre reiterar que a Dignidade valorativa de cada ser vivo existe no campo da Ética, porém não no campo do Direito, alheio a esta valoração moral.

Ost (1995, p. 257), citado por Leite (2007, p. 144), afirma que o que se procura com o biocentrismo é uma igualdade de direitos, não uma igualdade de fato e uma igualdade de consideração, e não igualdade de tratamento. Esse pensamento é adequado sob uma perspectiva Ética e não jurídica positiva. Primeiramente, porque uma igualdade teórica não resolveria adequadamente o problema fático. Ou a igualdade é objetiva e plena ou não existe, e uma igualdade formal entre direitos dos seres humanos e dos demais seres vivos é impraticável. Por outro lado, uma igualdade teórica continuaria a não proteger os interesses dos demais seres vivos. Finalmente, valer-se de igualdade de consideração significaria adicionar um elemento puramente valorativo ao Direito, o que foge à predisposição desta ciência.

O Direito defende os interesses naturais, porém isso não o torna ciência com sujeição ecocêntrica ou biocêntrica. É autodeterminação, leia-se Dignidade Humana, o foco do Direito e de sua sujeição e, pelo fato mesmo, antropocêntrico.

Nesse sentido, ingressando no cerne do título deste tema, cabem curiosas constatações acerca da história da sujeição biocêntrica e ecocêntrica. Ferry (2009) aponta, sendo desconhecido pelo grande público que, derivado do pensamento do direito romano antigo em que ao juiz caberia estabelecer ordem sobre todas as coisas, de maneira que entre os séculos XXIII e XXVIII, ações judiciais contra animais eram mais comuns do que se pode imaginar. Em tais ações, movidas contra porco que comeu a mão de uma criança, ratos que invadiram uma igreja, carunchos que causavam prejuízos a vinhas etc., o autor aponta que havia o reconhecimento de tais animais como "sujeitos de direito", o que revela ser esta questão muito antiga. Assim, o porco que comeu a mão da criança foi ele próprio punido com a morte, com execução feita por carrasco, sem ter o dono do porco sofrido qualquer responsabilização. Com o humanismo evidenciado no séc. XVIII, este reconhecimento da sujeição dos animais perdeu força.

O movimento ganhou força novamente, de acordo com Ferry (2009), no fim da década de 1970. Em verdade, aponta o autor que naquela mesma década houve comoção no vale de Sierra Nevada (Estados Unidos) relativa aos direitos de montanhas e rochedos. Explica o autor que, na época, o governo norte-americano permitiu que a Walt Disney construísse um parque naquela região, decisão administrativa combatida judicialmente por Sierra Club, uma das mais fortes associações de ecologistas do mundo. Na ação, foram utilizados argumentos de que o parque temático iria destruir o equilíbrio da região. Assim, para impedir a construção, 
o advogado da entidade pedia o reconhecimento dos diretos legais das florestas, dos oceanos, dos rios e do meio ambiente em geral, cogitando, inclusive, representação proporcional para as árvores no poder legislativo. Em função disso, a natureza teria uma personalidade jurídica e poderia ser defendida por advogado ou uma associação.

Ainda impregnada pela defesa do ambiente, a década de 1970 também teve como marco a Declaração Universal do Direito dos Animais da UNESCO/78. Esta soft law, aprovada em Bruxelas em 1978, apesar de defender o "direito dos animais", o faz sem fulcro no biocentrismo/ecocentrismo, já que defende uma supremacia humana perante os animais. No preâmbulo, a Declaração afirma que todos os animais possuem direitos. Todavia, logo o item 2 do art. $3^{\circ}$ autoriza o abate do animal desde que de modo instantâneo e indolor; no mesmo sentido, o animal criado para a alimentação (humana) deve ser cuidado de modo que lhe cause o menor sofrimento, dor e angústia possível (art. $9^{\circ}$ ). Eis, novamente, a problemática novamente na concepção positiva do Direito: ou se dota o animal com Direitos equiparáveis aos humanos (em que pese haver colisão entre direitos) ou se admite que, dentro da Ciência do Direito, o não humano acaba tendo que se submeter às necessidades humanas, procurando-se, ao máximo, realizar a Dignidade Humana resguardando os interesses daquele. A crítica do positivismo a essa ideia reside no fato de seus defensores assumirem uma postura teórica de equiparação de direitos entre os não humanos e o ser humano e, na prática, apresentarem a impossibilidade em fazer tal equiparação.

Hodiernamente, a matéria não perdeu força. O conteúdo da Constituição Política da Republica do Equador é grande exemplo disto. $\mathrm{O}$ art. 71 daquela Constituição afirma que a natureza, ou Pacha Mama, em que se reproduz e se realiza a vida, "tem o direito" que seja respeitada integralmente sua existência e sejam respeitadas a manutenção e a regeneração dos seus ciclos vitais, estrutura, função e processos evolutivos. Enfatiza, ainda, que qualquer pessoa, comunidade, povo ou cidadãos poderá exigir da autoridade pública o cumprimento "dos direitos da natureza." 13

Observa-se uma notória atribuição de direitos à Pacha Mama (em quíchua, deidade máxima, a "Mãe Natureza"), algo inusitado, dado o seu caráter superior à natureza em si, já que é uma deidade. Não há notícia de outra Constituição ou lei laica que tenha tomado semelhante atitude em elevar a natureza/deidade ao grau de sujeito de direito.

Tudo indica que a elevação a sujeito de direito de Pacha Mama deve ser interpretada com ressalvas, já que o art. 74 da mesma Constituição afirma que as pessoas, a comunidade, os povos e os cidadãos "têm direito" de se beneficiar do ambiente e das riquezas naturais que lhes viabilizem qualidade de vida. E complementa afirmando que os serviços ambientais não serão suscetíveis de apropriação, sendo sua produção, prestação, uso e aproveitamento regulados pelo Estado. ${ }^{14}$ De um lado, diz-se que a natureza tem direitos. De outro, diz-se que as pessoas podem usufruir do ambiente e das riquezas naturais em busca de uma qualidade de vida. Há uma clara oposição entre Direitos dos seres humanos e o Direito de Pacha Mama de que sejam respeitadas sua existência e a manutenção e regeneração de seus ciclos vitais. 
Ao que se apresenta, a situação parece, como no caso da Declaração de Direitos dos Animais, se tratar de uma falsa atribuição de sujeição, em que se utiliza a expressão "a natureza tem direito" ou "os animais têm direito" como um designativo de preceitos a serem observados pelos seres humanos, estes sim, como sujeitos de direito. Em sendo, a Constituição Equatoriana, recente (EQUADOR, 2008), resta esperar como se dará a sua aplicação mediante esta aparente colisão de normas constitucionais, uma vez que, segundo pesquisado, até maio de 2012, nem a Corte Constitucional nem tampouco a Corte Suprema (Corte Nacional de Justiça) não haviam julgado nenhum caso relacionado ao Direito Ambiental.

$O$ principal e justificado receio dos defensores da visão biocêntrica e ecocêntrica acerca da visão antropocêntrica de sujeição de Direito é a convalidação de todas as atitudes humanas, ao ambiente natural e aos demais seres vivos, por mais nocivas que sejam, em função de uma supremacia humana.

Infelizmente, (ainda) existem defensores de uma visão antropocêntrica pautada no pensamento "posso tudo porque sou humano": o ser humano não como centro da ciência do Direito, mas como centro de todas as ciências e mesmo do Universo em si. Não é esta a melhor visão antropocêntrica, uma vez que absurda e distante da realização da Dignidade Humana. Não parece ser esta a visão de sujeição antropocêntrica seguida pelo positivismo.

Em verdade, por mais contraditório que pareça, na Dignidade Humana, ou seja, na autodeterminação humana, residem a observância e o respeito aos ideais e às responsabilidades ecocêntricas e biocêntricas. Conforme já foi dito, a Dignidade Humana pode ser realizada por meio de normas que objetivem imediatamente a sua realização (direito à vida, direito à saúde, direito ao meio ambiente ecologicamente equilibrado), bem como normas que não tenham este objetivo imediato.

Ferry, nesse sentido, acaba ele próprio reconhecendo parte da problemática da atribuição de direitos aos animais:

Então, de certa forma, sim, você tem razão, as discussões sobre os direitos animais ou das árvores são uma forma de retorno às visões antigas do mundo. $\mathrm{O}$ problema, a princípio, é que, hoje, quando alguém tem direitos, tem também deveres, algo que para os animais e as árvores é um tanto complicado (FERRY, 2010, online).

O ser humano limitar o ser humano é o preceito da autodeterminação. Eis que a humanidade, ao longo de muitos séculos de estudo e desenvolvimento de diversas teses filosóficas, entendeu que ao Direito cabe a proteção dos interesses ecocêntricos e biocêntricos, antes somente defendidos filosoficamente e, eventualmente, teologicamente. Assim, tais interesses devem ser respeitados como forma de realização da Dignidade Humana. Respeitar tais interesses, repita-se à exaustão, não constitui em alteração da sujeição de Direito, sempre antropocêntrica.

O estudado até este momento permitiu a fixação de bases, dentro de um pensamento positivo, da relação simbiótica entre Direito, proteção ambiental e ser humano. Foi possível constatar que ser o Direito sustentado por um pensamento positivo não afasta a sua proteção ambiental, inclusive relativamente a bens jurídicos não humanos. Pode-se, assim, verificar 
que, pelo papel da norma dentro do Direito, haverá necessidade de sua observância independente do valor ético subjetivo que o bem jurídico tutelado possua. Com isso, é possível avançar para a relação entre o Direito Fundamental e a proteção ambiental, já que o Direito Fundamental é a maior expressão hierárquica dentro do sistema normativo de um Estado.

\section{CONCLUSÕES}

Partindo-se das premissas designadas neste estudo, ser sujeito de direitos não equivale ao designativo ter direitos. Ser sujeito de direitos significa ser simultaneamente o ourives e a joia em relação à Ciência do Direito: a norma que limita a ação humana é criada pelo ser humano. E a norma é objeto do Direito, sempre com o objetivo de realizar a Dignidade Humana que é, em última análise, a autodeterminação humana.

Porque o ser humano é o único animal capaz de se autodeterminar é que se diz que o Homo sapiens sapiens é o único sujeito de direitos possível. O ser humano cria normas para regrar a si mesmo, vale dizer, imputa comportamento por meio da normativa. Tal normativa somente tem sentido em ser atribuída, no pensamento positivista, àquele que detém efetivamente a autodeterminação.

O Direito pode impor normas que atendam interesses alheios e, muitas vezes, contrários aos do ser humano, de forma a atender às necessidades do ambiente natural e das criaturas viventes. Esta preocupação ecológica não torna, no entanto, a natureza como um todo e as criaturas vivas em sujeitos de direito.

Os Direitos Fundamentais constituem a mais elevada e distinta categoria de Direitos na ordem de um Estado, sendo a máxima expressão da Dignidade Humana. E o reconhecimento do ambiente como Direito Fundamental marcou definitivamente a mudança do paradigma cientifico jurídico do objeto tutelado pelas normas. A preocupação de um Direito ainda antropocêntrico em sua sujeição assumia uma tutela mais ampliada em seu objeto. A vontade humana moldou a vontade humana, de modo a definir a importância da proteção ambiental pela Ciência do Direito.

Com isso, o fato de não se reconhecer a natureza ou os animais e vegetais como sujeitos da Ciência do Direito não os coloca em um patamar inferior de proteção de seus interesses. Muito ao contrário. Se somente o ser humano pode determinar o seu próprio comportamento, cabe-lhe uma missão única: ser dotado com o poder para destruir e utilizá-lo, ao invés, para construir e respeitar.

Por fim, de se ponderar: o reconhecimento unilateral, pelos seres humanos, de sujeição não humana de Direitos, ainda que superados todos os problemas lógico-científicos, seria a melhor solução? Não seria o reconhecimento da sujeição de direitos, neste caso, justamente porque feito unilateralmente, por um polo apenas, ou seja, no caso, pelos seres humanos uma simples forma de imposição de normas às espécies não humanas e, portanto, um não verdadeiro reconhecimento. 


\title{
SUBJECTION OF RIGHTS, ENVIRONMENT AND EXPANDED ANTHROPOCENTRISM
}

\begin{abstract}
There are many questions about the real role of the individual in sciences and, likewise, if such role could be played by non-human figures. From modernity, a vigorous struggle began, with ups and downs, about the possibility of attributing the role of subjects of rights to animals, nature and other non-human entities. From considerations developed based on the analysis of expanded anthropocentrism, this paper intends to demonstrate the capacity of a science bearing a human subject to be, nevertheless, concerned with the needs of the environment.
\end{abstract} Keywords: Subjection of rights. Anthropocentrism. Ecologic perspectives. Biocentrism. Ecocentrism.

\section{SUJECIÓN DE DERECHOS, MEDIO AMBIENTE Y ANTROPOCENTRISMO ALARGADO}

\section{RESUMEN}

Existen muchos cuestionamientos sobre el real papel del ser humano en las ciencias y, de la misma forma, si este papel podría ser desempeñado por figuras no humanas. Ya a partir de la modernidad, se inició un vigoroso embate, con altos y bajos, sobre la posibilidad de atribuirse a los animales, a la naturaleza y a otras entidades no humanas el papel de sujetos de derechos. A partir de algunas ponderaciones desarrolladas por el análisis del antropocentrismo alargado, el presente trabajo pretende demostrar la capacidad de una ciencia con un sujeto humano, pero preocupado con las necesidades del ambiente.

Palabras-clave: Sujeción de derechos. Antropocentrismo. Ecovisiones. Biocentrismo. Ecocentrismo.

\footnotetext{
1 "[...]daß in ihr die lebende und die tote Katze (s. v. v.) zu gleichen Teilen gemischt oder verschmiert sind [...]", ou sua tradução equivalente "[...] contendo em si mesma o gato vivo e o gato morto (desculpem-me a expressão) misturados ou dispostos em partes iguais[...]".

2 "Preamble. The right to live is the right from which all other rights stem" (Hague declaration on the environment, 1989).

3 Gramaticalmente, dignidade tem raiz latina (lat. dignitas), que significava grandioso, excelência, de peso, majestoso, merecedor e virtuoso (lat. amplitudo, excellentia, gravitas, maiestas, mereo mereor, promereo promereor, virtus). Por sua vez, o vocábulo humanidade, derivado de humano (lat. humanus), deriva também do latim humanitatem, para indicar natureza humana. Fonte: Humanity (2017).

4 "24. O summam Dei patris liberalitatem, summam et admirandam hominis foelicitatem! 25. Cui datum id habere
} 
quod optat, id esse quod velit. 26. Bruta simul atque nascuntur id secum afferunt (ut ait Lucilius) e bulga matris quod possessura sunt. 27. Supremi spiritus aut ab initio aut paulo mox id fuerunt, quod sunt futuri in perpetuas aeternitates. 28. Nascenti homini omnifaria semina et omnigenae vitae germina indidit Pater. 29. Quae quisque excoluerit illa adolescent, et fructus suos ferent in illo. 30. Si vegetalia planta fiet, si sensualia obrutescet, si rationalia caeleste evadet animal, si intellectualia angelus erit et Dei filius. 31. Et si nulla creaturarum sorte contentus in unitatis centrum suae se receperit, unus cum Deo spiritus factus, in solitaria Patris caligine qui est super omnia constitutus omnibus antestabit." em tradução livre do texto do autor, Magnífica liberdade de nosso Deus-Pai. Admirável destino do homem que recebeu a concessão de obter seus desejos, o que ele queira. No momento em que nascem, as bestas trazem consigo, do ventre materno, tudo o que tem e precisarão para sua vida. Os espíritos superiores, desde o princípio ou pouco depois, foram criados para ser o que serão eternamente. $O$ Pai celestial confiou ao homem, desde o nascimento, sementes de toda espécie e de toda a vida. E, segundo cada homem as cultive, germinarão e darão frutos. Se vegetarem, serão plantas; se emocionais, serão animais; se racionais, serão animais celestes; se intelectuais, serão anjos ou Filho de Deus. E se não está contente com o destino da criatura cultivada, se apega no centro de seu ser, transformando-se em um espírito a sós com Deus em sua cálida acolhida e, já que foi colocado acima de todas as coisas, as sobrepujará (DELLA MIRANDOLA, 2017).

5 "Quis hunc nostrum chamaeleonta non admiretur? 33. Aut omnino quis aliud quicquam admiretur magis?" (DELLA MIRANDOLA, Pico. op. cit.).

6 "Jeder Mensch ist Mensch kraft seines Geistes, der ihn abhebt von der unpersönlichen Natur und ihn aus eigener Entscheidung dazu befähigt, seiner selbst bewusst zu werden, sich selbst zu bestimmen und sich und die Umwelt zu gestalten." (DURIG, 1956, p. 125).

7 "[...] são as normas jurídicas o objeto da ciência jurídica, e a conduta humana só o é na medida em que é determinada nas normas jurídicas como pressuposto ou conseqüência, ou - por outras palavras - na medida em que constitui conteúdo de normas jurídicas." (KELSEN, 1976, p. 103).

8 Possível é afirmar que a Dignidade Humana ganhou força no pós-Segunda Guerra e particularmente a partir do Julgamento de Nuremberg, período que determinou o enfraquecimento do positivismo clássico e admissão de que há valores por de trás das normas: postulado pós-positivista. Radbuch afirmou que o postulado positivista de que "a lei é a lei" e deveria ser aplicada deixou muitos juristas alemães inertes diante de leis arbitrárias e de conteúdo criminoso, impedindo-os de qualquer questionamento moral ou qualquer reserva pessoal ante as normas aplicadas. Vale citar: "Der Konflikt zwischen der Gerechtigkeit und der Rechtssicherheit dürfte dahin zu lösen sein, daß das positive, durch Satzung und Macht gesicherte Recht auch dann den Vorrang hat, wenn es inhaltlich ungerecht und unzweckmäßig ist, es sei denn, daß der Widerspruch des positiven Gesetzes zur Gerechtigkeit ein so unerträgliches Maß erreicht, daß das Gesetz als ,unrichtiges Recht' der Gerechtigkeit zu weichen hat. Es ist unmöglich, eine schärfere Linie zu ziehen zwischen den Fällen des gesetzlichen Unrechts und den trotz unrichtigen Inhalts dennoch geltenden Gesetzen; eine andere Grenzziehung aber kann mit aller Schärfe vorgenommen werden: wo Gerechtigkeit nicht einmal erstrebt wird, wo die Gleichheit, die den Kern der Gerechtigkeit ausmacht, bei der Setzung positiven Rechts bewußt verleugnet wurde, da ist das Gesetz nicht etwa nur ,unrichtiges' Recht, vielmehr entbehrt es überhaupt der Rechtsnatur. Denn man kann Recht, auch positives Recht, gar nicht anders definieren als eine Ordnung und Satzung, die ihrem Sinne nach bestimmt ist, der Gerechtigkeit zu dienen." (RADBRUCH, 1946, p. 107).

9 "The question is not, Can they reason? Nor Can they talk? but, Can they suffer?"

10 Art. 121 do Código Penal brasileiro.

11 Art. 32 da Lei 9.605/98, a Lei de Crimes Ambientais.

12 Definido pelo citado autor como ideal de reciprocidade.

13 Art. 71.- La naturaleza o Pacha Mama, donde se reproduce y realiza la vida, tiene derecho a que se respete integralmente su existencia y el mantenimiento y regeneración de sus ciclos vitales, estructura, funciones y procesos evolutivos. Toda persona, comunidad, pueblo o nacionalidad podrá exigir a la autoridad pública el cumplimiento de los derechos de la naturaleza. Para aplicar e interpretar estos derechos se observaran los principios establecidos en la Constitución, en lo que proceda. El Estado incentivará a las personas naturales y jurídicas, y a los colectivos, para que protejan la naturaleza, y promoverá el respeto a todos los elementos que forman un ecosistema.

14 Art. 74. - Las personas, comunidades, pueblos y nacionalidades tendrán derecho a beneficiarse del ambiente y de las riquezas naturales que les permitan el buen vivir. Los servicios ambientales no serán susceptibles de apropiación; su producción, prestación, uso y aprovechamiento serán regulados por el Estado. 


\section{REFERÊNCIAS}

ABBAGNANO, Nicola. Dicionário de filosofia. Tradução Alfredo Bosi. São Paulo: Mestre Jou, 1982.

ALEXY, Robert. Teoria dos direitos fundamentais. Tradução Virgílio Afonso da Silva. São Paulo: Malheiros, 2008.

AYALA, Patryck de Araújo. A proteção jurídica das futuras gerações na sociedade do risco global: o direito ao futuro na ordem constitucional brasileira. In: LEITE, José Rubens Morato; FERREIRA, Heline Sivini (Org.). Estado de direito ambiental: tendências, aspectos constitucionais e diagnósticos. Rio de Janeiro: Forense Universitária, 2004. p. 229-268.

BENJAMIN, Antônio Herman. Constitucionalização do ambiente e ecologização da Constituição brasileira. In: CANOTILHO, Joaquim José Gomes; LEITE, José Rubens Morato (Org.). Direito constitucional ambiental brasileiro. São Paulo: Saraiva: 2007. p. 85-111.

BENTHAM, Jeremy. An introduction to the principles of morals and legislation. 1907. Disponível em: < http://www.econlib.org/library/Bentham/bnthPML18.html\#anchor_a122>. Acesso em: 20 jul. 2017.

BÍBLIA. A. T. Gênesis. In: BÍBLIA, Português. A Bíblia Sagrada: Antigo e Novo Testamento. Tradução de João Ferreira de Almeida. Edição rev. e atualizada no Brasil. Brasília: Sociedade Bíblia do Brasil, 1969. p. 69-72.

BOBBIO, Norberto. A era dos direitos. Tradução Carlos Nelson Coutinho. 10. ed. Rio de Janeiro: Campus, 1992.

CANOTILHO, José Joaquim Gomes. Prefácio. In: CANOTILHO, Joaquim José Gomes; LEITE, José Rubens Morato (Org.). Direito constitucional ambiental brasileiro. São Paulo: Saraiva: 2007. p. 15-20.

CAPRA, Fritjof. A teia da vida: uma nova compreensão científica dos sistemas vivos. Tradução Newton Roberval Eichemberg. São Paulo: Cultrix, 2006.

CASTRO, Ariadne Mansu de. Antropocentrismo, biocentrismo e direito dos animais. 2008. Disponível em <http://www.cenedcursos.com.br/antropocentrismo-biocentrismo-direito-animais.html>. Acesso em 17 set. 2017.

DEL VECCHIO, Giorgio. A justiça. Tradução Antonio José Brandão. 4. ed. São Paulo: Saraiva, 1960.

DELLA MIRANDOLA, Pico. Oratio de hominis dignitate. In: . Discurso sobre la dignidad del hombre. E-book. Disponível em: <http://www.scribd.com/doc/25331560/ Discurso-sobre-la-dignidad-del-hombre-Pico-Della-Mirandola > . Acesso em: 20 jul. 2017. DÜRIG, Günter. Der Grundsatz der Menschenwürde. Entwurf eines praktikablen Wertsys- 
tems der Grundrechte aus Art. 1 Abs. I in Verbidung mit Art, 19 Abs. II des Grundgesetzes. Archiv des Öffentlichen Rechts (AöR), Tübingen, n. 81, 1956.

ELIA, Marco. Metamorfose da ciência: uma breve história do movimento. 2007. Disponível em: <http://pt.scribd.com/doc/87479786/Metamorfose-da-Ciencia-Marco-Elia >. Acesso em: 10 set. 2017.

EQUADOR. Constitución de la República del Ecuador. 2008. Disponível em <http:// www.asambleanacional.gov.ec/documentos/constitucion_de_bolsillo.pdf $>$. Acesso em: 10 set. 2017.

FERRAJOLI, Luigi. Los fundamentos de los derechos fundamentales. Tradução Perfecto Andrés. 4. ed. Madrid: Trotta, 2009.

FERRY, Luc. A nova ordem ecológica: a árvore, o animal e o homem. Tradução Rejane Janowitzer. Rio de Janeiro: Difiel, 2009.

. Entrevista com Luc Ferry. Pensador critica nova "ecochatice”. Revista Galileu, n. 222, jan. 2010. Disponível em: <http://revistagalileu.globo.com/Revista/Common/0,EMI11392317579-2,00-PENSADOR+CRITICA+NOVA+ECOCHATICE.html. Acesso em: 17 set. 2017.

FIORILlO, Celso Antônio Pacheco. Curso de direito ambiental brasileiro. 7. ed. São Paulo: Saraiva, 2006.

GARCIA, Maria. Limites da ciência: a dignidade da pessoa humana: a ética da responsabilidade. São Paulo: Revista dos Tribunais, 2004.

. Direitos humanos e a constitucionalização do direito internacional: o direito/dever de ingerência. In: BONAVIDES, Paulo (Coord.). Revista Latino Americana de Estudos Constitucionais, Belo Horizonte, 2003, n. 8, p. 76-94, jan./jun. 2008.

HART, Herbert Lionel Adolphus. El concepto de derecho. Tradução Genaro R. Carrio. 2. ed. Buenos Aires: Abeledo-Perrot, 1977.

HERVADA, Javier. O que é direito? Tradução Elza Maria Gasparotto. São Paulo: Martins Fontes, 2006.

HUMANITY. Dictionary.com. Disponível em: <http://dictionary.reference.com/browse/ humanity >. Acesso em: 20 jul. 2017.

KANT, Immanuel. Fundamentação da metafísica dos costumes. 2006. Disponível em: $<$ http://www.consciencia.org/kantfundamentacao.shtml>. Acesso em: 20 jul. 2017.

KELSEN, Hans. Teoria pura do direito. Tradução João Baptista Machado. 4. ed. Coimbra: Armênio Amado, 1976.

. Teoria pura do direito. Tradução João Baptista Machado. 5. ed. São Paulo: Martins Fontes, 1996. 
LEITE, José Rubens Morato. Dano ambiental: do individual ao coletivo extrapatrimonial. São Paulo: Revista dos Tribunais, 2003.

LEITE, José Rubens Morato. Sociedade de Risco e Estado. In: CANOTILHO, Joaquim José Gomes; LEITE, José Rubens Morato (Org.). Direito constitucional ambiental brasileiro. São Paulo: Saraiva: 2007. p. 156-220.

MIAILLE, Michel. Introdução crítica ao direito. Tradução Ana Prata. 3. ed. Lisboa: Editorial Estampa, 2005.

MIRRA, Álvaro Luiz Valery. Ação civil pública e a reparação do dano ao meio ambiente. São Paulo: Juarez de Oliveira, 2002.

OST, François. A natureza à margem da lei: a ecologia à prova do direito. Tradução Joana Chaves. Lisboa: Instituto Peaget, 1997.

RADBRUCH, Gustav. Gesetzliches Unrecht und übergesetzliches Recht. Zurique: SJZ Schweizerische Juristen Zeitung, 1946.

RICOEUR, Paul. O justo 1: a justiça como regra moral e como instituição. São Paulo: [s.n.], 2008.

RODRIGUES, Marcelo Abelha. Instituições de direito ambiental. São Paulo: Max Limonad, 2002.

ROMANO, Santi. Princípios de direito constitucional geral. Tradução Maria Helena Diniz Santi. São Paulo: RT, 1977.

ROSS, Alf. Direito e justiça. Tradução Edson Bini. Bauru: EDIPRO, 2003.

SARLET, Ingo Wolfgang, Dignidade da pessoa humana e direitos fundamentais na Constituição Federal de 1988. 8. ed. Porto Alegre: Livraria do Advogado, 2010.

SCHRÖDINGER, Erwin. Die gegenwärtige Situation in der Quantenmechanik. Naturwissenschaften, Germany, v. 23, n. 48, p. 807-849, nov. 1935.

SENDIM, José de Sousa Cunhal. Responsabilidade civil por danos ecológicos: da reparação do dano através de restauração natural. Coimbra: Coimbra Ed., 1998.

SOFFIATI, Arthur. A natureza é sujeito de Direito? 2009. Disponível em $<$ http://www. sosanimalmg.com.br/sub.asp?pag=artigos\&amp;id=39 >. Acesso em: 17 set. 2017.

Submetido: 1 ago. 2017

Aprovado: 27set. 2017 